\title{
BMJ Open Pronounced haemodynamic changes during and after robotic-assisted laparoscopic prostatectomy: a prospective observational study
}

\author{
Michael T Pawlik, ${ }^{1}$ Christopher Prasser, ${ }^{2}$ Florian Zeman, ${ }^{3}$ Marion Harth, ${ }^{1}$ \\ Maximilian Burger, ${ }^{4}$ Stefan Denzinger, ${ }^{4}$ Sebastian Blecha (1) ${ }^{2}$
}

To cite: Pawlik MT, Prasser C, Zeman F, et al. Pronounced haemodynamic changes during and after roboticassisted laparoscopic prostatectomy: a prospective observational study. BMJ Open 2020;10:e038045. doi:10.1136/ bmjopen-2020-038045

- Prepublication history and additional material for this paper are available online. To view these files, please visit the journal online (http://dx.doi. org/10.1136/bmjopen-2020038045).

Received 25 February 2020 Revised 06 August 2020 Accepted 10 August 2020

\section{Check for updates}

(c) Author(s) (or their employer(s)) 2020. Re-use permitted under CC BY-NC. No commercial re-use. See rights and permissions. Published by BMJ.

${ }^{1}$ Department of Anaesthesiology, Caritas-Krankenhaus Sankt Josef Regensburg, Regensburg, Bayern, Germany

${ }^{2}$ Department of Anaesthesiology, Universitätsklinikum

Regensburg, Regensburg, Bayern, Germany

${ }^{3}$ Centre for Clinical Studies, Universitätsklinikum Regensburg, Regensburg, Bayern, Germany

${ }^{4}$ Department of Urology, Caritas-Krankenhaus Sankt Josef Regensburg, Regensburg, Germany

Correspondence to

Dr Sebastian Blecha;

Sebastian.Blecha@ukr.de

\section{ABSTRACT}

Objectives Robotic-assisted laparoscopic prostatectomy (RALP) is typically conducted in steep Trendelenburg position (STP). This study investigated the influence of permanent $45^{\circ}$ STP and capnoperitoneum on haemodynamic parameters during and after RALP. Design Prospective observational study.

Setting Haemodynamic changes were recorded with transpulmonary thermodilution and pulse contour analysis in men undergoing RALP under standardised anaesthesia.

Participants Informed consent was obtained from 51 patients scheduled for elective RALP in a University Medical Centre in Germany.

Interventions Heart rate, mean arterial pressure, central venous pressure (CVP), Cardiac Index (Cl), systemic vascular resistance (SVR), Global End-Diastolic Volume Index (GEDI), global ejection fraction (GEF), Cardiac Power Index (CPI) and stroke volume variation (SVV) were recorded at six time points: 20 min after induction of anaesthesia (T1), after insufflation of capnoperitoneum in supine position (T2), after $30 \mathrm{~min}$ in STP (T3), when controlling Santorini's plexus in STP (T4), before awakening in supine position (T5) and after $45 \mathrm{~min}$ in the recovery room (T6). Adverse cardiac events were registered intraoperatively and postoperatively.

Results All haemodynamic parameters were significantly changed by capnoperitoneum and STP during RALP and partly normalised at $\mathrm{T6}$. $\mathrm{Cl}, \mathrm{GEF}$ and $\mathrm{CPI}$ were highest at T6 (Cl: 3.9 vs $2.2 \mathrm{~L} / \mathrm{min} / \mathrm{m}^{2}$; GEF: 26 vs $22 \%$; CPI: 0.80 vs $0.39 \mathrm{~W} / \mathrm{m}^{2} ; p<0.001$ ). CVP was highest at T4 (31 vs $7 \mathrm{~mm} \mathrm{Hg}, p<0.001$ ) and GEDI at T6 (819 vs $724 \mathrm{~mL}$ $\mathrm{m}^{2}, \mathrm{p}=0.005$ ). Mean SVR initially increased (T2) but had decreased by $24 \%$ at $\mathrm{T} 6(\mathrm{p}<0.001)$. SW was highest at T5 (12 vs $9 \%, p<0.001$ ). Two of the patients developed cardiac arrhythmia during RALP and one patient suffered postoperative cardiac ischaemia.

Conclusions RALP led to pronounced perioperative haemodynamic changes. The combination of increased cardiac contractility and heart rate reflects a hyperdynamic situation during and after RALP. Anaesthesiologists should be aware of unnoticed pre-existing heart failure to worsen during STP in patients undergoing RALP.
Strengths and limitations of this study

- With the semi-invasive transpulmonary thermodilution and pulse contour analysis pronounced haemodynamic changes could be registered in a remarkable number of patients during and up to 1 hour after robotic-assisted laparoscopic prostatectomy (RALP).

- In our prospective observational study cohort $(n=51)$, perioperative cardiac complications were observed in $5.9 \%$.

- Based on the results, semi-invasive haemodynamic monitoring in patients undergoing RALP should be recommended and can influence anaesthetic management.

- The results of the study only reflect the haemodynamic changes towards a single-centre study.

- Due to the sample size, no firm conclusion can be drawn regarding overall cardiac adverse events or complications.

\section{INTRODUCTION}

Robotic-assisted laparoscopic prostatectomy (RALP) is a common and increasingly used alternative to open prostatectomy because of its benefits of minimal invasion, better short-term outcome and improved functional results. ${ }^{12}$ RALP requires steep Trendelenburg positioning (STP) (at least between $25^{\circ}-45^{\circ}$ head downposition) and capnoperitoneum (CP) ${ }^{34}$ This combination which may involve important pathophysiological changes in both the pulmonary and the cardiac system presents new challenges to anaesthesiologists. Besides pulmonary dysfunction with formation of atelectasis and increasing airway pressure, RALP leads to pronounced haemodynamic changes. ${ }^{45}$

Traditionally, haemodynamic parameters during RALP were monitored with a pulmonary artery catheter. ${ }^{6} 7$ Because of its complication rate, alternative methods for monitoring haemodynamic parameters 
have been controversially discussed. ${ }^{8}$ One alternative to perioperative haemodynamic measurement is continuous arterial pulse contour analysis. This technique is used here in a combination of transpulmonary thermodilution and pulse contour analysis enabling the determination and interpretation of changes in preload, afterload and cardiac function in different phases of RALP except direct measurement of the right heart as well as pulmonary and left atrial pressure. ${ }^{9}$ Parameters for detecting preload are the Global End-Diastolic Volume Index (GEDI) and central venous pressure (CVP), whereas systemic vascular resistance (SVR) is used for detecting afterload and Cardiac Index (CI) and global ejection fraction (GEF) for cardiac contractility. Furthermore, stroke volume variation (SVV) as a functional haemodynamic parameter resulting from the interaction between controlled mechanical ventilation and the cardiovascular system have been shown to predict increases in $\mathrm{CO}$ after volume substitution. ${ }^{1011}$ As a whole, these parameters enable the evaluation of cardiac function and could point to changes in volume status and cardiac responsiveness according to position changes during RALP.

This study investigated haemodynamic changes in patients undergoing RALP in permanent $45^{\circ} \mathrm{STP}$ and in awake patients up to 1 hour after RALP. The study hypothesis was that STP and CP significantly impair haemodynamic and cardiac function during and after RALP.

\section{METHODS}

The study protocol is attached as a online supplemental file 1 . Informed consent was obtained from 51 patients scheduled for elective prostatectomy at the Department of Urology of the University Medical Centre Regensburg in Germany. All patients were recruited between January and August 2015. Main exclusion criteria were age $>80$ years, a body mass index $(\mathrm{BMI})>40 \mathrm{~kg} / \mathrm{m}^{2}$, American Society of Anesthesia (ASA) physical status $>$ III, known cardiac failure or pulmonary hypertension (coronary heart disease, chronic heart insufficiency (New York Heart Association (NYHA) $\geq \mathrm{II})$ ) and severe pre-existing lung disease (bronchial asthma, chronic obstructive pulmonary disease and lung fibrosis).

\section{Anaesthesia}

The anaesthesia protocol standardised for drugs used during RALP was exclusively conducted by the same two anaesthesiologists (MTP and MH) throughout the entire study. Drug doses were based on the calculated ideal body weight. Patients received $2 \mathrm{mg}$ of midazolam for premedication and $0.1 \mathrm{mg}$ of piritramide per $\mathrm{kg}$ body weight for the placement of a Pulse Contour Cardiac Output (PiCCO) radial artery catheter for invasive blood pressure measurement under additional local anaesthesia. Anaesthesia was induced with propofol $(2-3 \mathrm{mg} / \mathrm{kg})$, remifentanil $(1.5 \mu \mathrm{g} / \mathrm{kg}$ bolus and continuous application of $0.3 \mu \mathrm{g} /$ $\mathrm{kg} / \mathrm{min})$ and rocuronium $(0.5 \mathrm{mg} / \mathrm{kg})$. After tracheal intubation with a 7.5 or $8.0 \mathrm{~mm}$ endotracheal tube, a central venous line was inserted into the internal jugular vein. Total intravenous anaesthesia was maintained with propofol (5-6mg/kg). A Bispectral Index (BIS Vista Monitor, Aspect Medical, Germany) between 40 and 50 was upheld during anaesthesia to secure a comparable state of anaesthesia throughout the study; remifentanil was reduced to $0.2 \mu \mathrm{g} / \mathrm{kg} / \mathrm{min}$ after induction of anaesthesia. Arterial blood pressure was kept stable with norepinephrine or volume with a maximum decrease of $20 \%$ of its preinduction value. All patients received volumecontrolled ventilation with positive end-expiratory pressure (PEEP) of $5 \mathrm{~mm} \mathrm{Hg}$, a basic respiratory rate of $10 /$ min and a constant tidal volume of $8 \mathrm{~mL} / \mathrm{kg}$ ideal body weight. Respiratory frequency was set to keep the end tidal $\mathrm{CO}_{2}$ between 30 and $40 \mathrm{~mm} \mathrm{Hg}$. Considerating our experience of STP with former procedures we decided to choose an inspiration to expiration (I:E) ratio of 1:1, although this may impair cardiac output due longer interval of increased intrathoracic pressure leading to a reduced venous blood return. Using an I:E of 1:2 under volume control ventilation would lead to higher peak pressures increasing the risk of pneumothorax during surgery. The inspiratory fractions of oxygen after the start of RALP were adjusted to maintain oxygen saturation above $96 \%$ or partial pressure of arterial oxygen above $90 \mathrm{~mm} \mathrm{Hg}$. Application of crystalloid fluid was restrictive and limited to a maximum of $8-10 \mathrm{~mL} / \mathrm{kg}$ ideal body weight before terminating vesico-urethral anastomosis. After extubation in head upposition, all patients were transferred to the recovery room under supplementation of oxygen via a face mask.

\section{Surgery}

RALP was exclusively conducted by the same highly experienced urologists (SD and $\mathrm{MB}$ ) using an intraperitoneal approach with the aid of a robotic system (DaVinci; Intuitive Surgical, Sunnyvale, California, USA), which generates a 3-dimensional view of the operating field. Pneumoperitoneum was created by insufflating carbon dioxide in horizontal supine position. Five surgical ports were placed, one for the camera, the others for insertion of the surgical instruments. For minimal intraoperative blood loss and optimal intraabdominal view, all patients were placed in permanent STP $\left(45^{\circ}\right.$ from horizontal), which is the maximal Trendelenburg angle of the surgical table (Maquet, MAQUET Vertrieb und Service Deutschland, Germany). Throughout surgery, intraabdominal pressure (IAP) was limited to $15 \mathrm{~mm} \mathrm{Hg}$, except during preparation of Santorini's plexus: here, IAP was increased up to $25 \mathrm{~mm} \mathrm{Hg}$ to reduce further venous bleeding. After removal of the prostate gland, the urethra was anastomosed to the urinary bladder and splinted via a urinary catheter. Before skin closure, carbon dioxide was released. The patient was returned to the horizontal position, and the skin wounds were closed.

\section{Measurement of haemodynamic parameters}

Haemodynamic parameters were recorded at six defined time points: 20 min after induction of anaesthesia under 
stable anaesthesia and steady-state conditions in supine position (T1), after insufflation of CP in supine position (T2), after $30 \mathrm{~min}$ in STP (T3), after the increase of IAP when controlling Santorini's plexus in STP (T4), after laparoscopy while in supine position before the end of the propofol infusion (T5) and after $45 \mathrm{~min}$ in the recovery room in supine position (T6). Haemodynamic parameters were measured with the PiCCO system (PULSION Medical Systems SE, Munich, Germany). To measure CI, three boluses of cold saline $\left(15 \mathrm{~mL},<8^{\circ} \mathrm{C}\right)$ were injected via transpulmonary arterial thermodilution. The following haemodynamic parameters were registered with PiCCO: heart rate (HR), systolic, diastolic and mean arterial blood pressure (SAP, and MAP), CVP, CI, SVR, GEDI, GEF, SVV and the Extravascular Lung Water Index (ELWI). The Cardiac Power Index (CPI) was calculated with the formula: $\mathrm{CPI}=\mathrm{CI} \times \mathrm{MAP} \times 0.0022$.

Besides haemodynamic parameters, patient characteristics (age, BMI and ASA classification), surgical details (duration of STP and surgery), ventilation settings (tidal volume, positive inspiratory pressure (PIP), plateau pressure, driving pressure $\left(\mathrm{P}_{\text {driv }}\right)$, PEEP, fractional inspired oxygen and endtidal $\mathrm{CO}_{2}$ ), cumulative dose of noradrenalin and the application rate of dobutamine were registered at each measuring time point. $\mathrm{P}_{\text {driv }}$ was calculated as the difference between plateau pressure and PEEP.

\section{Registration of perioperative adverse cardiac events}

Cardiac changes during RALP were monitored by means of continuous ECG recordings. Additionally, haemodynamic parameters were measured at defined time points. Each patient was postoperatively examined in the recovery room, 8 hours after transfer to the ward and on the next day. Any pathological findings on the ECG or adverse clinical conditions resulted in analyses such as the troponin test or 12-channel ECG.

\section{Sample size and statistical analysis}

No formal sample size calculation was conducted due to the explorative character of the study without a primary endpoint. Fifty patients were considered to be sufficient to analyse and depict haemodynamic parameters during RALP. Continuous data are presented as means and SD, categorical data as absolute and relative frequencies. The basis for all statistical analyses were linear mixed models, taking the repeated measurements for each patient into account. Haemodynamic changes over time were analysed by using time as fixed factor and patients as random factor. To identify clinical relevant parameters influencing CVP and $\mathrm{CI}$, age, BMI, driving pressure and noradrenalin were added as additional fixed factors next to time and to the random factor patient. Slopes with corresponding 95\% CIs are presented as effect estimates for these models. Differences between patients receiving dobutamine or not were analysed by using dobutamine (yes vs no) and time as fixed factors and patient as random factor. For the pairwise comparisons at each time point, least squares means where estimated within the model and the $p$ values were adjusted according to Bonferroni. All reported $\mathrm{p}$ values are two sided, and a $\mathrm{p}<0.05$ indicates significance. All analyses were done using the software SAS (V.9.4, SAS Institute) and the procedure proc mixed.

\section{Patient and public involvement}

Patients or the public were not involved in the design, or conduct, or reporting, or dissemination plans of our research.

\section{RESULTS}

Of 51 men undergoing RALP (mean age 64 years, SD \pm 8 years; mean BMI $\left.28.4 \mathrm{~kg} / \mathrm{m}^{2}, \mathrm{SD} \pm 4.0 \mathrm{~kg} / \mathrm{m}^{2}\right), 5(9.8 \%)$ were classified as ASA I, $38(74.5 \%)$ as ASA II and 8 $(15.7 \%)$ as ASA III. The median duration of the surgical procedure was $218 \mathrm{~min}$ (IQR: $120-357 \mathrm{~min}$ ), and the median duration of STP was $198 \mathrm{~min}$ (IQR: 109-331 min). Environmental variables are presented in table 1. Only $16 \%$ of the patients required noradrenalin at preparation of Santorini's plexus (T4).

\section{Haemodynamic parameters}

The mean values $( \pm \mathrm{SD}$ and $\mathrm{SD})$ of all haemodynamic parameters are listed in table 2. The time courses of haemodynamically documented parameters are shown in figure 1. Except for ELWI, the haemodynamic values of all measured parameters changed significantly during RALP and afterwards in the recovery room. CVP and GEDI as parameters of cardiac preload increased significantly during RALP. CVP significantly increased by up to $442 \%$ with the maximum value at T4 and normalised after surgery. GEDI continuously increased during RALP but did not drop to the initial value. SVR as a parameter of cardiac afterload increased shortly after insufflation of $\mathrm{CP}$ and continuously decreased over the course of RALP. At T5, mean SVR was less than $20 \%$ of the baseline value at T1. Parameters of cardiac contractility such as CI, GEF and CPI continuously increased over all measuring time points, stagnated only at $\mathrm{T} 4$ and showed the highest values in the recovery room (T6). At T6, CI increased up to $77 \%$ compared with T1 Mean CPI more than doubled between T1 and T6. SVV as a functional haemodynamic parameter increased significantly during RALP.

Table 3 shows the influence of age, BMI, duration of surgery, applied $\mathrm{P}_{\text {driv }}$ and the dose of noradrenalin on CVP and CI. Significant effects on all analysed parameters were registered over the duration of RALP compared with baseline (T1). Additionally, increased $\mathrm{P}_{\text {driv }}$ significantly reduced CVP $(\mathrm{p}<0.001)$. BMI and applied concentrations of noradrenalin did neither affect CVP nor CI.

\section{Adverse cardiac events}

At T2, 6 patients (6 of 51 patients, 11.8\%) showed cardiac deterioration with significant decreased CI (1.5 vs $\left.2.61 / \mathrm{min} / \mathrm{m}^{2}, \mathrm{p}=0.003\right)$ and increased SVR (6865 vs 2879 dyn $* \mathrm{~s}^{*} \mathrm{~cm}^{-5}, \mathrm{p}=0.001$ ) (see table 4 ). In these cases, additionally to already applied norepinephrine after the 
Table 1 Environmental variables $(n=51)$

\begin{tabular}{|c|c|c|c|c|c|c|}
\hline & \multicolumn{6}{|c|}{ Perioperative measuring time points } \\
\hline & T1 & T2 & T3 & T4 & T5 & T6 \\
\hline Table position & $0^{\circ}$ & $0^{\circ}$ & $45^{\circ}$ & $45^{\circ}$ & $0^{\circ}$ & $0^{\circ}$ \\
\hline Capnoperitoneum & No & Yes & Yes & Yes & No & No \\
\hline Vasopressor use (n (\%)) & $48 / 51(94)$ & $38 / 51(75)$ & $25 / 51(49)$ & $8 / 51(16)$ & $22 / 51(43)$ & $0 / 51(0)$ \\
\hline $\begin{array}{l}\text { Crystalloid solution (mL/kg) } \\
M( \pm S D)\end{array}$ & $2.9( \pm 1.0)$ & $4.5( \pm 1.2)$ & $6.2( \pm 1.6)$ & $8.0( \pm 1.9)$ & $10.2( \pm 2.6)$ & $12.6( \pm 3.5)$ \\
\hline \multicolumn{7}{|l|}{ Respiratory parameters } \\
\hline $\begin{array}{l}\text { Peak inspiratory pressure }\left(\mathrm{cmH}_{2} \mathrm{O}\right) \\
\mathrm{M}( \pm \mathrm{SD})\end{array}$ & $16.6( \pm 3.4)$ & $28.3^{\star}( \pm 6.8)$ & $31.5^{\star}( \pm 4.9)$ & $33.4^{\star}( \pm 5.2)$ & $21.2^{\star}( \pm 4.8)$ & - \\
\hline Driving pressure $\left(\mathrm{cmH}_{2} \mathrm{O}\right) \mathrm{M}( \pm \mathrm{SD})$ & $10.2( \pm 3.2)$ & $21.8^{*}( \pm 5.6)$ & $24.6^{\star}( \pm 4.9)$ & $26.5^{\star}( \pm 5.1)$ & $14.3^{*}( \pm 4.7)$ & - \\
\hline Tidal volume $(\mathrm{mL} / \mathrm{kg}) \mathrm{M}( \pm \mathrm{SD})$ & $7.04( \pm 0.92)$ & $7.00( \pm 1.03)$ & $6.89( \pm 1.04)$ & $6.90( \pm 0.99)$ & $7.06( \pm 1.11)$ & - \\
\hline $\mathrm{FiO}_{2}(\%) \mathrm{M}( \pm \mathrm{SD})$ & $57( \pm 9)$ & $55( \pm 5)$ & $54( \pm 5)$ & $56( \pm 9)$ & $56( \pm 9)$ & - \\
\hline Endtidal $\mathrm{CO}_{2}(\mathrm{~mm} \mathrm{Hg}) \mathrm{M}( \pm \mathrm{SD})$ & $34( \pm 1)$ & $35( \pm 2)$ & $34( \pm 2)$ & $34( \pm 2)$ & $34( \pm 2)$ & - \\
\hline
\end{tabular}

$\mathrm{M}=$ mean, $\mathrm{SD}=\mathrm{SD},{ }^{*} \mathrm{p}<0.05 \mathrm{vs}$ baseline $\mathrm{T} 1$ (analysed for respiratory parameters); $\mathrm{T} 1: 20 \mathrm{~min}$ after induction of anaesthesia, $\mathrm{T} 2$ : after insufflation of capnoperitoneum, T3: after $30 \mathrm{~min}$ in steep Trendelenburg position (STP), T4: when controlling Santorini's plexus in STP, T5: after laparoscopy while in supine position before the end of anaesthesia, T6: after $45 \mathrm{~min}$ in the recovery room. $\mathrm{FiO}_{2}$, fractional inspired oxygen.

start of dobutamine infusion cardiac parameters stabilised, but still three patients $(5.9 \%)$ developed higherlevel cardiac abnormalities: two patients intraoperatively showed changes in bigeminy on the ECG but did not require any further intervention except monitoring in an intermediate care unit. Another patient with no previous history of coronary disease experienced postoperative cardiac ischaemia: after reporting angina symptoms in the recovery room, he received postoperative coronary angiography with stent implantation because of significant coronary stenosis. These three patients showed elevated troponin levels after surgery. Anamnestic, four of six patients with additionally infused dobutamine suffered from well-controlled arterial hypertension.

\section{DISCUSSION}

The present study shows pronounced changes in the haemodynamic parameters of 51 men undergoing RALP and in the recovery room postoperatively. The main results were: (1) besides ELWI, all haemodynamic parameters significantly changed during RALP compared with baseline; (2) cardiac contractility increased during RALP with the highest values in the recovery room; (3) cardiac preload significantly increased during RALP and (4) $5.9 \%$ of the patients developed adverse cardiac abnormalities with elevated troponin levels.

The combination of transpulmonary thermodilution with pulse contour analysis is a valid method for calculating haemodynamic parameters and cardiac contractility during various conditions. ${ }^{12} 13$ During RALP, haemodynamic changes have been sufficiently registered with this method. ${ }^{9}$ Based on our results, semi-invasive haemodynamic monitoring with PiCCO in patients undergoing RALP should be recommended to detect cardiac and haemodynamic deteriorations immediately. This monitoring allows a quick adaption of anaesthetic management during and after RALP.

\section{CVP and GEDI (cardiac preload)}

In this study, CP and STP during RALP increased cardiac preload based on the increase in venous backflow, which significantly increased CVP and GEDI. This result is comparable with the findings in other studies. ${ }^{914}$ Based on elevated IAP during T4, GEDI was only slightly reduced, and the drop-in preload was mirrored by slightly reduced $\mathrm{CI}$ at T4; however, CVP remained stable during T4. CVP was reversely influenced by increasing $\mathrm{P}_{\text {driv }}$ in the multivariate analysis, which can be explained by the reduced volume preload due to increased intrathoracic pressure because of mechanical ventilation.

\section{Blood pressure and SVR (cardiac afterload)}

In this study, blood pressure changed significantly during RALP. Postoperative SAP was probably due to pain or to neuroendocrine reaction from operative tissue trauma as strong as in STP without catecholamine (ie, none of the patients received norepinephrine in the recovery room). SVR increased at the start of CP (T2) and decreased below the baseline value (T1) during STP. The decrease in SVR after STP may have been caused by a combination of reduced vascular elastance due to elevation of the legs and increased abdominal pressure, the delayed release of endogenous vasoactive substances and the activation of sympathetic tone. These changes in SVR are comparable with the results of Falabella $e t a l$, who measured SVR with a transoesophageal echo-Doppler probe. ${ }^{15}$ In contrast, another study showed a significant increase in SVR in all phases of RALP and a decrease to values below baseline values at the end of surgery by means of 


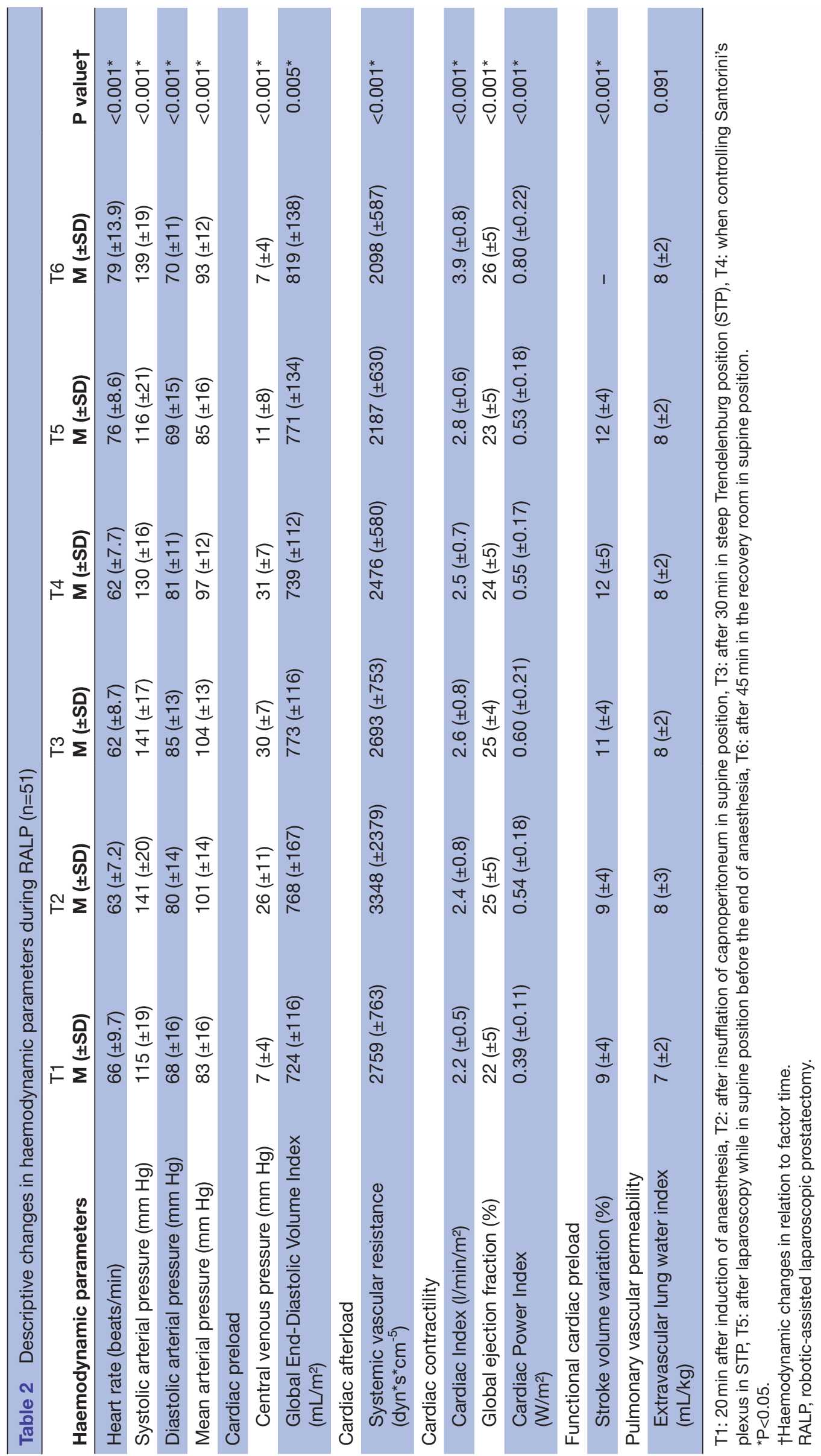



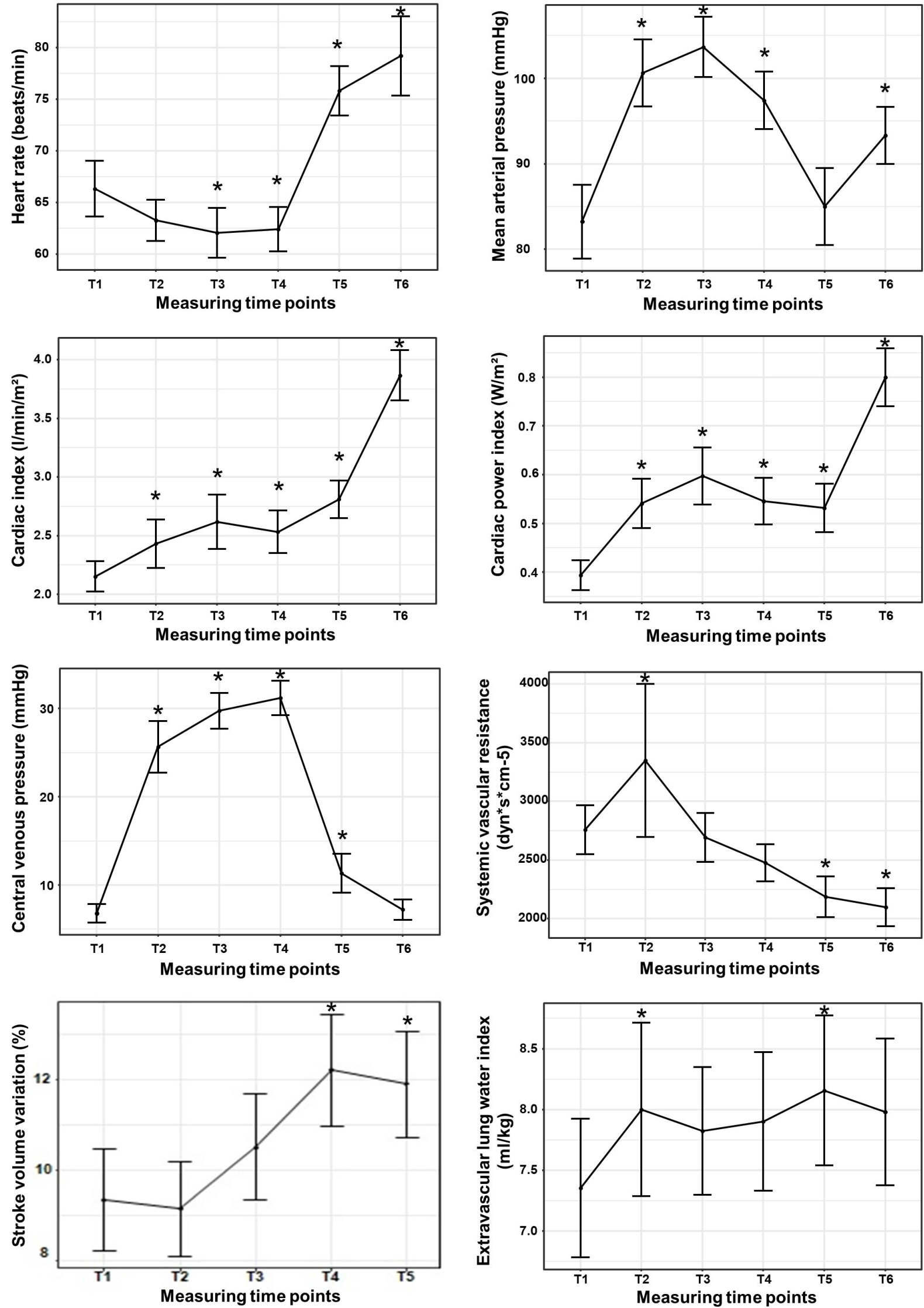

Figure 1 Changes in haemodynamic parameters during RALP notes: T1: 20 min after induction of anaesthesia, T2: after insufflation of capnoperitoneum in supine position, T3: after $30 \mathrm{~min}$ in steep Trendelenburg position (STP), T4: when controlling Santorini's plexus in STP, T5: after laparoscopy while in supine position before the end of anaesthesia, T6: after $45 \mathrm{~min}$ in the recovery room in supine position. Data are presented as mean values and $95 \%$ Cls for each time point, ${ }^{*} p<0.05$ vs baseline $\mathrm{T} 1$. 
Table 3 Influence of age, body mass index (BMI|), duration of surgery and applied driving pressure on central venous pressure and cardiac index in a multivariable analysis

\begin{tabular}{|c|c|c|c|}
\hline Dependent variable & Independent variable & Slope $(95 \% \mathrm{Cl})$ & $P$ value \\
\hline & Age & $0.09(-0.11$ to, 0.29$)$ & 0.38 \\
\hline & BMI & $-0.20(-0.61$ to 0.21$)$ & 0.33 \\
\hline & Duration of surgery & $0.24(-17.96$ to 18.43$)$ & 0.98 \\
\hline & Driving pressure & 0.63 (0.41 to 0.86$)$ & $<0.001^{*}$ \\
\hline \multirow[t]{11}{*}{ Central venous pressure } & Time points: & & \\
\hline & T1 & Reference & \\
\hline & T2 & 11.52 (8.17 to 14.86$)$ & $<0.001^{*}$ \\
\hline & T3 & 13.83 (9.99 to 17.67$)$ & $<0.001^{*}$ \\
\hline & T4 & 14.09 (9.89 to 18.29$)$ & $<0.001^{*}$ \\
\hline & T5 & $1.93(-0.38$ to 4.24$)$ & 0.1 \\
\hline & Age & $0.003(-0.02$ to 0.02$)$ & 0.77 \\
\hline & BMI & $0.01(-0.03$ to 0.05$)$ & 0.67 \\
\hline & Duration of surgery & 1.89 (0.09 to 3.59$)$ & $0.04^{*}$ \\
\hline & Driving pressure & $-0.01(-0.03$ to 0.01$)$ & 0.52 \\
\hline & Noradrenalin & $-0.52(-2.01$ to 0.98$)$ & 0.5 \\
\hline \multirow[t]{6}{*}{ Cardiac Index } & Time points: & & \\
\hline & $\mathrm{T} 1$ & Reference & \\
\hline & T2 & $0.36(0.05$ to 0.66$)$ & $0.022^{*}$ \\
\hline & T3 & 0.54 (0.17 to 0.90$)$ & $0.004^{*}$ \\
\hline & $\mathrm{T} 4$ & 0.46 (0.06 to 0.86$)$ & $0.025^{\star}$ \\
\hline & T5 & 0.66 (0.42 to 0.89$)$ & $<0.001^{*}$ \\
\hline
\end{tabular}

95\% Cl, BMI, T1: 20 min after induction of anaesthesia, T2: after insufflation of capnoperitoneum in supine position, T3: after 30 min in steep Trendelenburg position (STP), T4: when controlling Santorini's plexus in STP, T5: after the laparoscopic procedure while in supine position before the end of anaesthesia; \#patient-related, surgical-related, ventilatory and time-related confounders for multivariable analysis for haemodynamic parameter of cardiac preload and contractility. ${ }^{*} \mathrm{P}<0.05$.

pulse contour monitoring. ${ }^{9}$ Remarkably, only $16 \%$ of the patients needed noradrenalin at preparation of Santorini's plexus (T4). Obviously, stimulation and preparation of Santorini's plexus elevates blood pressure by releasing catecholamines or by inducing pain, which significantly reduces the need for catecholamines.

\section{$\mathrm{CI}, \mathrm{GEF}$ and CPI (cardiac contractility)}

Various studies have reported changes in CI ranging from a decrease by $11 \%$ during CP and STP to significant increases by more than $20 \% \cdot{ }^{16}$ Rosendahl et al found a decrease in CI in the CP phase followed by an increase in CI after STP until the end of RALP. ${ }^{9}$ Other studies did not show any significant differences in CI during RALP. ${ }^{615}$ In the present study, and CI continuously increased during RALP with the highest values in the recovery room (T6). Only at T4, CI stagnate because of the increase in IAP from 15 to $25 \mathrm{~mm} \mathrm{Hg}$. Even after restoration of supine position in the recovery room (T6), CI and CPI remained almost twice as high as at the beginning of RALP (T1), which described the cardiac work load during and after RALP with the pronounced influence of CP and STP on heart function. The combination of rising cardiac contractility and HR shows a hyperdynamic situation during and after RALP, resulting in higher cardiac oxygen consumption.

Another important variable to impact cardiac output is the ventilation regime during RALP surgery. As the $\mathrm{I}: \mathrm{E}$ ratio was set to $1: 1$ in the study protocol we probably affected the cardiac output by prolonged positive pressure in the thoracic system leading to a diminished venous return to the right heart. One has to take into consideration that STP is characterised by high peak pressures above $30 \mathrm{~cm} \mathrm{H}_{2} \mathrm{O}$ and in some cases near to $40 \mathrm{~cm}$ $\mathrm{H}_{2} \mathrm{O}$. This may increase the risk of intraoperative pneumothorax and bringing the patient immediately into lifethreatening danger. On the other hand, an I:E ratio of 1:2 may be necessary to exhale increase $\mathrm{CO}_{2}$ during $\mathrm{CP}$ and maintain normal acid-base balance.

\section{SVV (functional cardiac preload)}

SVV as a dynamic preload parameter can only be measured in volume-controlled ventilated patients and predict the increase in stroke volume after fluid challenge. In this study, SVV significantly increased during RALP with the highest value at the end of surgery (T5). These results are based on the increase in volume preload due to the 


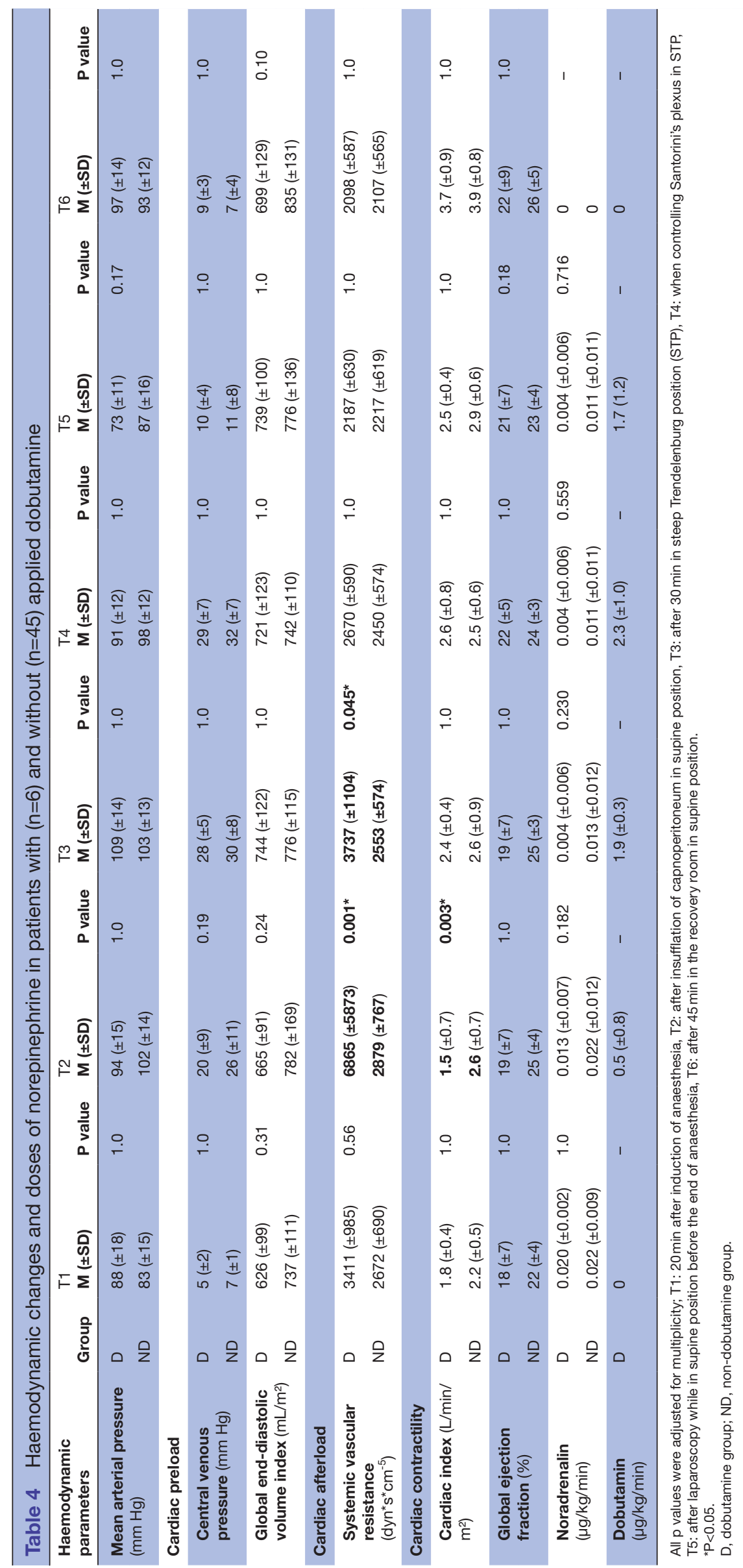


application of CP and STP during RALP. Additionally, PIP and $\mathrm{P}_{\text {driv }}$, which partially reflect intrathoracic pressure, significantly increased at the start of CP. This increase could consequently result in the large difference in airway pressure responsible for the significant increase in SVV. Haas et al, who registered SVV by pulse contour analysis with the VigileoTM monitoring system (Edwards LifesciencesTM, USA), did not find any significant change. ${ }^{17}$ Rosendal et al only noted a significant increase in SVV at the start of CP (comparable to T2 in our study). ${ }^{9}$ These differing results show the limitations of SVV measurement during RALP. Therefore, we do not consider the use of SVV under STP and CP good guidance for volume resuscitation and optimisation in cardiac output.

\section{Extravascular Lung Water Index}

ELWI-as a parameter for increased pulmonary permeability or volume overload with left heart failure and lung oedema-did not show any significant changes despite STP and a significant increase in stroke volume and CI due to the Frank Starling-mechanism. No comparable results for patients undergoing RALP are available in the literature. However, changes in ELWI have only been found in patients receiving delta-aminolevulinic acid to visualise tumour margins prior to radical retro pubic prostatectomy. ${ }^{18}$ The registered intraoperative values of ELWI during open prostatectomy were comparable to our results, but ELWI significantly increased in the postanaesthesia care unit based on the characteristic of deltaaminolevulinic acid, which increases capillary leakage in the lung.

\section{Adverse cardiac events complications}

According to the literature, between $70 \%$ and $80 \%$ of prostatectomies in the USA are conducted with robotic assistance. ${ }^{19}{ }^{20}$ Despite the advantages of the RALP technique ${ }^{21}$ the robotic surgery requires CP in STP and may involve various complications. ${ }^{22}$ A current study found that whole-blood viscosity significantly increased in 58 patients undergoing RALP, but no severe postoperative complications were observed. ${ }^{23}$ In this study, three patients (5.8\%) developed adverse cardiac events like heart insufficiency and ischaemia. In a recent study, 38 of 600 patients (6.3\%) undergoing RALP experienced various complications according to the Clavien-Dindo classification, of whom only one patient $(0.2 \%)$ developed myocardial infarction. ${ }^{24} \mathrm{~A}$ systematic review showed a rate of $3.3 \%$ of major complications (11/335 patients) after laparoscopic radical prostatectomy. ${ }^{21}$ In otherwise healthy patients with latent heart failure, CP and STP may dramatically increase GEDI and SVR with a profound decrease in, CI and SAP. Increasing the doses of noradrenalin instead of using a 82-agonist such as dobutamine may result in severe heart failure by increasing cardiac afterload. We observed this phenomenon in six anamnestically healthy patients, in whom cardiac depression was antagonised with dobutamine and reduced norepinephrine, which normalised haemodynamic parameters.

\section{Strengths and limitations}

Because of logistic preoperative constraints, haemodynamic parameters were not measured prior to intubation. Based on the explorative study character, no formal sample size calculation was conducted. Due to the sample size, no firm conclusion can be drawn regarding overall cardiac adverse events or complications. A further limitation is the measurement of haemodynamic parameters with transpulmonary thermodilution and pulse contour analysis in STP.

Nevertheless, to the best of our knowledge, the current study shows pronounced haemodynamic changes in a remarkable number of patients during and after RALP. No other study has yet registered haemodynamic parameters in awake patients up to 1 hour after surgery. In our defined cohort, three cardiac complications were observed during RALP and in the recovery room.

\section{CONCLUSION}

In this study, RALP led to pronounced perioperative changes in haemodynamic parameters that could even be registered postoperatively in the recovery room. With the semi-invasive transpulmonary thermodilution and pulse contour analysis during and after RALP possible haemodynamic deterioration may be detected. Anaesthesiologists should watch out for sudden intraoperative decreases in blood pressure serving as a first indicator of initiate cardiac failure due to relative volume overload after STP and CP in clinically inapparent patients.

Acknowledgements We are grateful to Monika Schoell for the linguistic revision of the manuscript.

Contributors MTP: Idea for the study, study design, data collection, patient recruitment, draft of the manuscript and revision for important intellectual content; $\mathrm{CP}$ : data analysis and interpretation and revision of the manuscript for important intellectual content; FZ: data analysis and revision of the manuscript for important intellectual content; MH: Idea for the study, study design, patient recruitment, data collection and revision of the manuscript for important intellectual content; MB: acquisitions and interpretation of the data and revision of the manuscript for important intellectual content; SD: acquisitions and interpretation of the data and revision of the manuscript for important intellectual content; SB: Ethics approval, study design, data collection and analysis and revision of the manuscript for important intellectual content. All authors read and approved the final manuscript.

Funding The authors have not declared a specific grant for this research from any funding agency in the public, commercial or not-for-profit sectors.

Competing interests None declared.

Patient consent for publication Not required.

Ethics approval This single-centre prospective observational study was approved by the local institutional review board (Protocol no. 14-101-0107) and registered at the local Centre for Clinical Studies (Z-2014-0387-6, registered on 8 July 2014).

Provenance and peer review Not commissioned; externally peer reviewed.

Data availability statement Data are available on reasonable request. All data relevant to the study are included in the article or uploaded as online supplemental information. All data generated or analysed during this study are included in this published article and are available from the corresponding author on reasonable request.

Open access This is an open access article distributed in accordance with the Creative Commons Attribution Non Commercial (CC BY-NC 4.0) license, which permits others to distribute, remix, adapt, build upon this work non-commercially, and license their derivative works on different terms, provided the original work is 
properly cited, appropriate credit is given, any changes made indicated, and the use is non-commercial. See: http://creativecommons.org/licenses/by-nc/4.0/.

\section{ORCID iD}

Sebastian Blecha http://orcid.org/0000-0002-0634-7588

\section{REFERENCES}

1 Ficarra V, Novara G, Artibani W, et al. Retropubic, laparoscopic and robot-assisted radical prostatectomy: a systematic review and cumulative analysis of comparative studies. Eur Urol 2009;55:1037-63.

2 Porpiglia F, Morra I, Lucci Chiarissi M, et al. Randomised controlled trial comparing laparoscopic and robot-assisted radical prostatectomy. Eur Urol 2013;63:606-14.

3 Danic MJ, Chow M, Alexander G, et al. Anesthesia considerations for robotic-assisted laparoscopic prostatectomy: a review of 1,500 cases. J Robot Surg 2007;1:119-23.

4 Gainsburg DM. Anesthetic concerns for robotic-assisted laparoscopic radical prostatectomy. Minerva Anestesiol 2012;78:596-604.

5 Kilic OF, Börgers A, Köhne W, et al. Effects of steep Trendelenburg position for robotic-assisted prostatectomies on intra- and extrathoracic airways in patients with or without chronic obstructive pulmonary disease. Br J Anaesth 2015;114:70-6.

6 Lestar M, Gunnarsson L, Lagerstrand L, et al. Hemodynamic perturbations during robot-assisted laparoscopic radical prostatectomy in $45^{\circ}$ Trendelenburg position. Anesth Analg 2011;113:1069-75.

7 Choi EM, Na S, Choi SH, et al. Comparison of volume-controlled and pressure-controlled ventilation in steep Trendelenburg position for robot-assisted laparoscopic radical prostatectomy. J Clin Anesth 2011;23:183-8.

8 Rajaram SS, Desai NK, Kalra A, et al. Pulmonary artery catheters for adult patients in intensive care. Cochrane Database Syst Rev 2013;2:CD003408.

9 Rosendal C, Markin S, Hien MD, et al. Cardiac and hemodynamic consequences during capnoperitoneum and steep Trendelenburg positioning: lessons learned from robot-assisted laparoscopic prostatectomy. J Clin Anesth 2014;26:383-9.

10 Monnet X, Marik PE, Teboul J-L. Prediction of fluid responsiveness: an update. Ann Intensive Care 2016;6:111.
11 Teboul J-L, Monnet X, Chemla D, et al. Arterial pulse pressure variation with mechanical ventilation. Am J Respir Crit Care Med 2019;199:22-31.

12 Litton E, Morgan M. The PiCCO monitor: a review. Anaesth Intensive Care 2012;40:393-408.

13 Monnet X, Teboul J-L. Transpulmonary Thermodilution: advantages and limits. Crit Care 2017;21:147.

14 Kalmar AF, Foubert L, Hendrickx JFA, et al. Influence of steep Trendelenburg position and $\mathrm{CO}(2)$ pneumoperitoneum on cardiovascular, cerebrovascular, and respiratory homeostasis during robotic prostatectomy. Br J Anaesth 2010;104:433-9.

15 Falabella A, Moore-Jeffries E, Sullivan MJ, et al. Cardiac function during steep Trendelenburg position and CO2 pneumoperitoneum fo robotic-assisted prostatectomy: a trans-oesophageal Doppler probe study. Int J Med Robot 2007;3:312-5.

16 Hofer CK, Zalunardo MP, Klaghofer R, et al. Changes in intrathoracic blood volume associated with pneumoperitoneum and positioning. Acta Anaesthesiol Scand 2002;46:303-8.

17 Haas S, Haese A, Goetz AE, et al. Haemodynamics and cardiac function during robotic-assisted laparoscopic prostatectomy in steep Trendelenburg position. Int J Med Robot 2011;7:408-13.

18 Eichhorn V, Maerz A, Salomon G, et al. Hemodynamic effects of orally administered delta-ALA during radical prostatectomy. World $\mathrm{J}$ Urol 2013;31:371-6.

19 Singh I, Hemal AK. Robotic-Assisted radical prostatectomy in 2010. Expert Rev Anticancer Ther 2010;10:671-82.

20 Awad H, Walker CM, Shaikh M, et al. Anesthetic considerations for robotic prostatectomy: a review of the literature. J Clin Anesth 2012;24:494-504.

21 Cao L, Yang Z, Qi L, et al. Robot-Assisted and laparoscopic vs open radical prostatectomy in clinically localized prostate cancer: perioperative, functional, and oncological outcomes: a systematic review and meta-analysis. Medicine 2019;98:e15770.

22 Tourinho-Barbosa RR, Tobias-Machado M, Castro-Alfaro A, et al. Complications in robotic urological surgeries and how to avoid them: a systematic review. Arab J Urol 2018;16:285-92.

23 Shim J-W, Moon HK, Park YH, et al. Intraoperative changes in whole-blood viscosity in patients undergoing robot-assisted laparoscopic prostatectomy in the steep Trendelenburg position with pneumoperitoneum: a prospective nonrandomized observational cohort study. BMC Anesthesiol 2020;20:7.

24 Ferroni MC, Abaza R. Feasibility of robot-assisted prostatectomy performed at ultra-low pneumoperitoneum pressure of $6 \mathrm{mmHg}$ and comparison of clinical outcomes vs standard pressure of $15 \mathrm{mmHg}$. BJU Int 2019;124:308-13. 